\title{
O CUIDADO INTERDISCIPLINAR À FAMÍLIA DO PORTADOR DE TRANSTORNO MENTAL NO PARADIGMA DA DESINSTITUCIONALIZAÇÃO ${ }^{1}$ THE INTERDISCIPLINARY CARE TO FAMILY OF A MENTAL DISORDER SUBJECT UNDER THE DESINSTITUTIONALIZATION PARADIGM EL CUIDADO INTERDISCIPLINARIO A LA FAMILIA DEL PORTADOR DE TRASTORNO MENTAL SEGÚN EL PARADIGMA DE LA DESINSTITUCIONALIZACIÓN
}

\author{
MariaAngélica Pagliarini Waidman'2, IngridElsen ${ }^{3}$
}

\begin{abstract}
${ }^{1}$ Este estudo é parte da tese de doutorado "O cuidado às famílias de portadores de transtornos mentais no paradigma da desinstitucionalização", defendida em dezembro de 2004 na Universidade Federal de Santa Catarina (UFSC). A pesquisa foi financiada pelo CNPq.

${ }^{2}$ Enfermeira. Doutora em Filosofia da Enfermagem. Professora do Departamento de Enfermagem da Universidade Estadual de Maringá. Membro do Núcleo de Estudos, Apoio, Assistência à Família (NEPAAF).

${ }^{3}$ Enfermeira. Doutora em Ciência da Enfermagem. Professora do Mestrado da Universidade de Itajá. Membro do Grupo de Assistência, Pesquisa e Educação na área de Saúde da Família (GAPEFAM), junto ao Programa de Pós-Graduação em Enfermagem da UFSC e Presidente da REDE Laboratório de Estudos Interdisciplinares na Área de Família e de Saúde (LEIFAMS).
\end{abstract}

PALAVRAS-CHAVE: Desinstitucionalização. Família. Transtornos mentais.

KEYWORDS: Desinstitutionalization. Family. Mental desorders.

PALABRASCLAVE: Desinstitucionalización. Familia. Trastornos mentales.
RESUMO: Estudo bibliográfico que objetivou identificar nos estudos sobre desinstitucionalização e família as referências sobre o cuidado multi e interdisciplinar em saúde mental e apreender as categorias que emergem sobre a temática analisada. Foram analisados 41 estudos, 4 teses de doutorado e 10 dissertações de mestrado em enfermagem, 2 dissertações de medicina e 25 artigos publicados em periódicos nacionais de enfermagem e medicina. A técnica de análise de conteúdo utilizada foi a de Bardin. Foram encontradas três categorias: crítica ao cuidado oferecido por alguns profissionais; a necessidade de preparo do profissional para cuidar de famílias de portadores de transtorno mental e; a importância do profissional enquanto agente da desinstitucionalização e resinserção social do portador de transtorno mental. O trabalho interdisciplinar em saúde mental é um dos pressupostos para que a desinstitucionalização seja efetiva, porém, conforme pode ser observado neste estudo, os profissionais apresentam dificuldades em desenvolver essa forma de trabalho.

ABSTRACT: This bibliographic study attempted to identify the references concerning multi-care and interdisciplinary care in mental health from studies concerning desinstitucionalization and the family, as well as discover the categories that emerge from within the analysis. Forty-one, four doctoral dissertations in nursing, ten master's thesis's in nursing, two doctoral dissertations in medicine, and twenty-five articles published in national periodicals of nursing and/or medicine. The data analyzed according to the Bardin technique. Three categories were determined: criticism to the care offered by professionals; the need to prepare professional who will care for the mentally disturbed; and the importance of the professional as an agent of desinstitutionalization and social reinsertion of someone with a mental disturbance. Interdisciplinary work in mental health is one presuppositions for desinstitutionalization to be effective; however, as this study demonstrates, professionals face great challenges in developing this type of work.

RESUMEN: Estudio de tipo bibliográfico buscó identificar en los estudios acerca de la desinstitucionalización y la familia las referencias sobre el cuidado multi y interdisciplinario en salud mental y apuntar las categorias que emergen según en el tema. Fueron analizados cuarenta y una publicaciones, cuatro tesis y diez disertaciones de maestrado en enfermería, dos disertaciones de medicina y veinticinco articulos publicados en periodicos brasileños de enfermería y de medicina. El análisis del contenido utilizado en este estudio fue de Bardin. Fue señaladas tres categorías: crítica al cuidado ofrecido por algunos profesionales; la necesidad de preparación del profesional de la salud para cuidar de las familias del portadores de trastorno mental y; la importancia del profesional de la salud como agente de desinstitutionalización y reinserción social del portador de transtorno mental. El trabajo interdisciplinario de la salud mental es uno de los supuestos para que la desinstitutionalización sea eficaz, no obstante, en este estudio puede apreciarse que los profesionales de la salud presentaron dificultad para desarrollar esta forma de trabajo.
Endereço:

Maria Angélica Pagliarini Waidman

R. São João, 628, Apto 302 - 87.030-200

Zona Sete - Maringá, PR.

E-mail: angelicawaidman@hotmail.com
Artigo original: Pesquisa

Recebido em: 15 de fevereiro de 2005

Aprovação final: 06 de abril de 2005 


\section{INTRODUZINDO A PROBLEMÁTICA}

O cuidado em saúde mental, nos últimos anos, vem sofrendo algumas alterações em virtude da mudança de paradigma - da institucionalização para o da desinstitucionalização - ocorrida a partir de 1960 em outros países em 1980 no Brasil. Ressalto alguns pressupostos da desinstitucionalização, e entre outras coisas, chamo a atenção para: 1) a reformulação da relação terapêutica paciente-profissional e paciente-instituição e; 2) o transtorno mental possui um caráter inter e transdisciplinar e não pode ser reduzido ao tratamento de um único profissional, sendo o médico psiquiatra o profissional mais conhecido e valorizado.

O cuidado é o principal elemento para transformar o modo de viver e sentir o sofrimento do portador de transtorno mental e sua família no seu cotidiano. ${ }^{1}$ No entanto, cuidar da família dentro da perspectiva de desinstitucionalização significa dar espaço para que ela expresse e trabalhe esses sentimentos e encontre caminhos para viver melhor. ${ }^{1}$

A multi e interdisciplinaridade foram e são questões que contribuem para a trajetória da ação prática nas transformações das instituições de Trieste e no paradigma da desinstitucionalização, a relação entre o profissional e o cliente precisa ser uma relação entre pessoas e não relações de poder, e isso se faz a partir de uma proposta de trabalho interdisciplinar. ${ }^{2}$

Por isso, cuidar, nesse paradigma, envolve reformulação de conceitos e repensar velhas atitudes e pensamentos que geralmente segregavam e excluíam o portador de transtorno mental e sua família. E para nós que estamos acostumados a trabalhar isolados em nossa disciplina, isso torna-se um desafio, o qual devemos enfrentar para conseguirmos desenvolver um cuidado adequado em saúde mental.

A palavra cuidado é antiga e tem sua etiologia do latim cura, e era usada no contexto das relações de amor, de amizade. Expressava atitude de preocupação e de inquietação pela pessoa amada ou por um objeto de estimação. Também deriva da palavra cogitatus (de-cogitare), que tem o mesmo sentido de cura, porém com significado mais intenso como o de colocar atenção, mostrar interesse, revelar uma atitude de desvelo e preocupação. ${ }^{3}$

Já o termo multidisciplinaridade é empregado quando a solução de um problema necessita da obtenção de informação de duas ou mais ciências ou setores do conhecimento sem que as disciplinas envolvidas no processo sejam modificadas ou enriquecidas. A interdisciplinaridade é o nível em que a interação entre várias disciplinas ou setores heterogêneos de uma mesma ciência conduz a interações reais, a uma certa reciprocidade no intercâmbio, levando a um enriquecimento mútuo.

É possível, a partir dos conceitos acima citados, perceber que o trabalho multidisciplinar é mais fácil de ser conseguido do que o interdisciplinar, porém, parece-me que em saúde mental ainda estamos longe de conseguir fazer esse tipo de trabalho. Apesar de contarmos com uma equipe formada, parece que cada profissional está empenhado em desenvolver a sua parte no todo. Exemplo disso é o que acontece em algumas instituições que conheço o trabalho, ele funciona assim: o psicólogo atende, encaminha para o psiquiatra ou para as oficinas com enfermeiros e psicólogos, ou então; o psiquiatra atende e encaminha para as outras atividades do serviço com outros profissionais. Na maioria das vezes a atitude a ser tomada com esse cliente não é discutida entre os profissionais, cada um faz a sua parte isoladamente, ocorrendo, inclusive no prontuário, uma evolução diferenciada de cada profissional. Observo assim que apesar de termos uma equipe ao nosso lado e estarmos desenvolvendo algumas atividades em conjunto ainda carecemos de um trabalho interdisciplinar efetivo em saúde mental.

Assim sendo este estudo apresenta uma pequena parte dos resultados de uma tese de doutorado, cujos achados sobre multi e interdisciplinaridade na saúde mental foram considerados de grande valor para a prática profissional com vistas ao cuidado à família no paradigma da desinstitucionalização.

\section{Objetivos}

Identificar nos estudos sobre desinstitucionalização e família as referências sobre o cuidado multi e interdisciplinar em saúde mental e apreender as categorias que emergem sobre a temática analisada.

\section{MÉTODO}

Foi realizada uma pesquisa bibliográfica. Esse tipo de pesquisa é desenvolvido a partir de material já elaborado, constituído, principalmente, de livros e artigos científicos. ${ }^{5}$ Nesse caso, a pesquisa foi realizada exclusivamente a partir de fontes bibliográficas (teses, dissertações e artigos de periódicos). A técnica de análise utilizada foi de conteúdo, ${ }^{6}$ que constitui-se no conjunto de instrumentos metodológicos, em constante aperfeiçoamento, que se aplica às comunicações. Trata-se de um método empírico dependente do tipo de 
comunicação e do objetivo que se queira alcançar ao analisar. Nessa técnica se trabalha as palavras e suas significações, ou seja, é uma busca de outras realidades através da mensagem, usando um mecanismo de dedução com base nos indicadores construídos a partir de uma amostra de mensagens particulares. ${ }^{6}$

\section{Amostra}

A seleção do material se deu a partir de quatro critérios: 1) ter como autor enfermeiros ou médicos (em casos de teses e dissertações), ou ter sido publicado em periódicos de enfermagem ou medicina (em casos de artigos)*; 2) ser realizado com famílias de portadores de transtornos mentais, podendo ou não estar associado ao tema desinstitucionalização; 3 ) ter sido publicado entre os anos de 1980 a 2001; 4) constar nas bases de dados Literatura Latino-Americana e do Caribe em Ciências da Saúde (LILACS); Bibliografia Brasileira de Enfermagem (BBENF); banco de teses da CAPES e Biblioteca Virtual em Saúde Pública (BVS-SP).

A seleção do material se deu a partir das palavras-chave família e desinstitucionalização associadas a outras, como: reforma do sistema de saúde ou reforma psiquiátrica; equipe de assistência ao paciente ou equipe interdisciplinar de saúde e; saúde mental ou centros/serviços comunitários de saúde mental. $\mathrm{O}$ número de palavras-chave variou devido à base de dados consultada.

Foram analisados 41 estudos, sendo 4 teses de doutorado em enfermagem, 10 dissertações de mestrado em enfermagem, 2 dissertações de medicina e 25 artigos publicados em periódicos nacionais da área enfermagem e medicina. Destes, 28 são pesquisas (T-Enf, D-Enf e D-Med e P), seis são relatos de experiência (RL), seis reflexão teórica (RT) e uma revisão de literatura (RL).

No estudo bibliográfico que utiliza a análise de conteúdo como técnica de análise, a coleta, o registro e análise dos dados acontecem concomitantemente, ou seja, coleta-se, registra-se, analisa-se cada estudo individualmente para depois vê-los como um todo e interpretá-los. Isso ocorreu no período de outubro de 2002 até março de 2004.

\section{ANALISANDO, DISCUTINDO E INTER- PRETANDO OS DADOS}

Analisando os estudos, o que mais se destacou foi a questão ética no cuidado. Eles ressaltam a necessidade de haver ética no cuidado ao portador de transtorno mental e sua família, respeitando-se a sua cidadania e promovendo a sua reabilitação. Esta ética envolve também o respeito ao cuidado familial desenvolvido dentro da família, o compartilhar do saber do profissional com o saber familial. Um cuidado ético preocupa-se com tudo que envolve o ser humano, com tudo que o rodeia, ou seja, com a sua singularidade, igualdade, desigualdades, harmonias e conflitos. Não pode ser baseado numa única estratégia; deve ser livre, criativo e não pode ter medo de inovar.

Aí então me coloco a fazer algumas indagações a respeito do compromisso com o trabalho e com a pessoa, o ser humano portador de transtorno mental, principalmente por parte daquele profissional que não está satisfeito com seu trabalho ou que não concorda com a desinstitucionalização e não quer o portador de transtorno mental em sua unidade em hospital geral. Como podemos mostrar interesse e preocupação por alguém que é diferente e que muitas vezes nos causa medo e repulsa, que é chamado louco? Neste ponto, chamo a atenção para a questão da responsabilidade profissional. Trata-se de uma atitude relacionada ao ser humano, ao seu semelhante, cuja necessidade a ser satisfeita, naquele momento, depende do profissional. É nesse momento que se faz necessário o cuidado multi e interdisciplinar. Buscar junto a outros profissionais de saúde a solução para esses problemas ajuda na elaboração e proposição de um cuidado digno e ético para essa pessoa que esteja precisando de ajuda nesse momento.

Então precisamos ser éticos e ter uma atitude de cuidado que provoque preocupação e sentido de responsabilidade. ${ }^{3}$ Isso vem corroborar os achados deste estudo quando os autores analisados colocam a importância do cuidado ético que eles descrevem como aquele que é preocupado com a qualidade do serviço de saúde oferecido. Que a assistência seja digna e satisfatória e a família saia do serviço com suas necessidades atendidas. Um cuidado preocupado não

\footnotetext{
* Mesmo sabendo que a atuação em saúde mental com vistas a desinstitucionalização é multidisciplinar e interdisciplinar, optei por analisar estudos somente de enfermagem e medicina pela questão do número de trabalhos existentes na área e pelo tempo para o desenvolvimento da pesquisa. Porém acredito que isso se constituiu uma limitação do estudo, mas mesmo assim os resultados mostraram a importância da interdisciplinaridade na área, pois os artigos, mesmo publicados em periódicos de enfermagem e medicina, muitos eram de autoria multidisciplinar.
} 
somente com a intervenção, mas com a promoção e com prevenção da saúde da família como um todo. Um cuidado ético que focaliza a produção da vida do outro, da qualidade, da reinserção, da reconquista do direito de ser gente, de ser cidadão. E acreditamos que para atingir toda a dimensão deste cuidado é necessário lançar mão do trabalho interdisciplinar.

Acredito que para haver um cuidado ético é preciso profissionais comprometidos com a ética, preparados para identificar os recursos disponíveis na comunidade e saber interferir e interagir na hora adequada. Profissionais que saibam ouvir, avaliar, identificar, planejar e intervir com famílias, neste caso as de portadores de transtornos mentais; que saibam oferecer um cuidado diferenciado, que dê suporte à dor do paciente e a oportunidade para ele expressar seus sentimentos e suas expectativas.

Quando falo em um cuidado ético em relação ao portador de transtorno mental, penso também nas condições de vida das pessoas que cuidam dele - na maioria das vezes profissionais de nível médio - muitas vezes desinformadas, mal-remuneradas e sem condições dignas para desenvolver um cuidado adequado, fazendo-nos inferir que a ética do cuidado também não chegou até elas. Assim, me pergunto: como estas pessoas podem oferecer um cuidado ético, se muitas vezes não o recebem? Para oferecer um cuidado de qualidade o profissional deve desenvolver capacidades como: facilidade de contato interpessoal, competência para interagir e comunicar-se, consideração dos aspectos emocionais presentes nas relações. Deve também preservar sua auto-estima e estimular a dos outros, usar a empatia, respeitar o outro na sua individualidade e, acima de tudo, ter um comportamento ético, que envolve o compromisso e o envolvimento profissional.

Não obstante, na minha vivência profissional, muitos auxiliares de enfermagem e de recreação que cuidam de portadores de transtornos mentais e acompanham os familiares nas reuniões queixam-se de cansaço, de insatisfação, e pior, vêm tirar dúvidas simples sobre comportamentos e atitudes dos clientes que os familiares expõem e eles não souberam esclarecer. São essas pessoas (des)preparadas para cuidar que compõem a equipe multiprofissional/interdisciplinar, são elas que na maioria das vezes atendem nas instituições psiquiátricas do Brasil, sejam hospitais do tipo manicômio, CAPSs, emergências psiquiátricas, $\mathrm{HDs}$, ou qualquer outra.

A mudança de comportamento da equipe interdisciplinar para trabalhar com o portador de transtorno mental oferecendo um cuidado ético precisa partir de sua sensibilidade de cuidado, de uma avaliação introspectiva da sua própria vida comparada à vida do outro. É uma mudança de atitude, na forma de cuidar e de como sentiu-se cuidado ao longo de sua vida. Isto, entretanto, não é tão fácil assim, pois mobiliza sentimentos, pensamentos que muitas vezes não se quer mobilizar, ficando mais fácil ser superficial na prestação do cuidado, se é que com essa superficialidade essa atividade pode ser chamada de cuidado.

Infelizmente o problema não pode ser resolvido de uma maneira muito simples. É necessário mudar conceitos e preconceitos arraigados há anos, é preciso haver uma mudança na forma de pensar das pessoas que cuidam do portador de transtorno mental, para que este possa ser realmente visto como um ser humano digno de respeito e que merece viver livre na sociedade, dentro das suas limitações, sendo estas respeitadas pelos seus semelhantes.

Os profissionais de saúde estiveram entre os principais atores da reforma psiquiátrica brasileira, através do Movimento de Trabalhadores em Saúde Mental (MTSM). Demonstrando, assim, a importância do profissional neste movimento, ${ }^{7}$ mas da mesma forma que estiveram unidos para lutar pela desinstitucionalização precisam se preocupar em desenvolver o trabalho interdisciplinar para, assim, atender todas as dimensões de necessidade de cuidado do portador de transtorno mental e de sua família.

Um dos precursores da desinstitucionalização mundial, Basaglia, já dizia que a multi e interdisciplinaridade é uma das questões que contribuem para a trajetória da ação prática nas transformações das instituições de Trieste. Um outro autor ao comentar a afirmação refere "[...] a relação de contrato implica a possibilidade de inventar novas estratégias de mediação, que vão das estratégias médicas ou psicológicas a estratégias culturais, sociais e políticas. Para tal propósito é preciso, no agir prático, superar a ambigüidade da psiquiatria[...]. A desinstitucionalização torna-se, portanto, um processo a um só tempo, de desconstrução dos saberes e práticas psiquiátricas[...]". 7:94-95

Observa-se assim, que o desafio da interdisciplinaridade em saúde mental nasceu junto com a proposta de mudança de paradigma nesta área e, mesmo assim, depois de quase 20 anos por essa busca pela desinstitucionalização ainda não conseguimos ultrapassar a barreira que nos impede de desenvolver um trabalho interdisciplinar com o portador de trans- 
torno mental e sua família. São vários os aspectos que impedem o desenvolvimento do trabalho interdisciplinar, um deles é o sentimento dos profissionais em relação ao portador de transtorno mental e ao movimento de desinstitucionalização.

O sentimento dos profissionais, não só os da área de saúde mental, em relação ao portador de transtorno mental é ambíguo, e se apresenta, algumas vezes, de forma pejorativa e negativa. ${ }^{8} \mathrm{Em}$ um dos estudos que discutiu a questão do sentimento dos profissionais em relação ao portador de transtorno mental apareceu a ambigüidade de sentimentos, variando desde o medo até a empatia: [...] os membros da equipe de enfermagem apresentam sentimentos os maisvariadospossizeis em relação a a atendimento do doentemental no Pronto Socorro Geral (PSG). Percebe-se que, na maioria das vezes, as expressões afetivas, mencionadaspelosfuncionários, em relação ao atendimento do doentemental, vinham associadas a outras, de aproximação ou distanciamento, indicando disponibilidade ou indisponibilidadepara prestar assistência a esse individuo. $O$ sentimento de dóoupena aparece, geralmente, ligadoàdisponibilidade internaparaajudaropacientepsiquiátrico, demonstrandomaiorcompreensĩo dos diversoscomportamentos apresentados pelosmesmos. A empatiatem um importantepapel na atenção aopacientepsiquiátrico, àmedida quepermitecompreendê-lo melhor(10P).

O exemplo acima mostra que alguns profissionais não estão preparados para lidar com o portador de transtorno mental e conseqüentemente com sua família. Já outro estudo discute essa ambigüidade de sentimento relacionando-o ao despreparo para cuidar e associando-o ao preconceito e a estigmatização. [...] o estigmadadoençamental a torna num assuntoponcoagradável para alguns profissionaiseleigos, fazendo-os apresentar um sentimentodeincompetênciaparacuidar (3P).

Essa sensação de incompetência pode estar associada à deficiência de comunicação entre o profissional, o cliente e sua família. Foram observadas deficiências na comunicação entre a família, a equipe interdisciplinar e o cliente, e isto, pode estar relacionado à desvalorização da comunicação pelos profissionais. [...] para eles (os membros familiares) os profissionais desconsideramo diálogocomopartedo tratamentoem doença mental [...]. A comunicaşão que deveria constituir-senum valioso instrumentoparaum cuidadoeficiente, provarvelmente, diluirse emmeio aopreconceito daqueles quecuidam(1D-Enf).

Outro estudo, porém, destacou que a comunicação é deficiente e quando ela existe é para persuadir e dominar:[...] a comunicação, basicamente, éfeita não só pelosenfermeiros, masportodos os outros membrosdaequipede enfermagem deste PSG (Pronto Socorro Geral), no sentido de persuadiroupedirconsentimentoparad manutençãodeatividades, comoa medicamentaçãoea contenção dopacientepsiquiátriCO(10P).

Em relação à comunicação da equipe multidisciplinar com o portador de transtorno mental e sua família, numa investigação de uma instituição psiquiátrica fechada e de grande porte, estudiosos verificaram que os profissionais atribuem grande importância à comunicação com os familiares de portadores de transtornos mentais; no entanto, revelam que essa comunicação é quase impossível, pela falta de tempo para fazê-la. Em relação à comunicação da equipe entre si e com os clientes verificaram que apesar de os profissionais afirmarem que se comunicam, o que realmente existe é uma circulação de informações. ${ }^{9}$ Neste sentido, podemos inferir que se a equipe não consegue desenvolver uma comunicação efetiva com a família, o cliente e entre si, o trabalho interdisciplinar torna-se ainda mais complexo e difícil de ser alcançado, apesar de extremamente importante para esta área do conhecimento.

A realidade mostrada pelas autoras em um hospital psiquiátrico ${ }^{9}$ demonstra que a mudança na formade atendimento ao portador de transtorno mental não se faz apenas na alteração da estrutura física e na equipe profissional, mas é preciso haver uma transformação no pensamento dessa equipe e na sua forma de agir dentro deste novo paradigma, ou seja, cuidar do portador de transtorno mental e de sua família requer um trabalho interdisciplinar efetivo e não a presença de profissionais de diferentes disciplinas trabalhando isoladamente.

Por isso, quando alguns autores falam que para haver a desinstitucionalização é preciso uma desconstrução de velhos conceitos, parece uma discussão utópica, mas não é. A realidade de um dos estudos analisados me levou a refletir sobre este assunto. A pesquisa feita compara grupos de usuários avaliando a sua reinserção social em locais onde a desinstitucionalização já está acontecendo. Mesmo assim, o autor identificou que também neste tipo de serviço a comunicação entre os profissionais e destes com a família e o cliente é deficiente e não há trabalho interdisciplinar. [...] apesar desta ampla gama de opções residenciaisedediversosserviçosprofissionaisdeacompanhamento dospacientes, ainda assim sediscute sobreafaltade umaintervençãoeficazporpartedos responsáveis das residênciase daequipe de acompanbamentoesobreafaltade uma integraçãomaisestreita entreelese o hospital de ondeprocederam ospacientes (7P). 
Ainda sobre a importância da comunicação efetiva da equipe com o cliente e a família, um estudo dá algumas dicas de como deve ser essa comunicação. [...] a aproximação desse universo exige do profissional paciência e sensibilidade na procura dos sentidos que brotam da experiência história de vida de cada um. Oprofissional precisa buscar conbecê-los de maneira global eabrangente, em suas múltiplas dimensôesexistenciais, tentando desenvolvermodalidade decuidado mais apropriadas às suas necessidades. Oprofissional precisa ver ofamiliar como uma pessoa sem reduzi-lo a sinaise sintomas.... precisareconhecerem profundidade os mecanismos queenvolvem a relação dosfamiliarescom seusparentes adoecidos. Oprofissional precisa ouvir a familia, pois as informações são fontes de dados valiosas para a elaboração de estratégiae práticas terapêuticas, assim como facilitar a comunicação com sua clientela, seja o doente, um familiar ou a família como um todo. Oprofissional deve colocarnocentro das atenções opotencial e a necessidade de cada familiarparticipantepara assim traçarem juntos as estratégias de cuidado (3D-Med).

Este relato mostra a importância de o profissional estar atento a todas as dimensões existenciais de cada ser humano que compõe a família, sem se esquecer de vê-la como um todo. Para isso é preciso que se pense num cuidado profissional adequado à família. A necessidade de cuidado profissional adequado ou a crítica ao (des)cuidado oferecido por algumas instituições foram retratados em 14 estudos. Dada a sua importância, destacamos alguns pontos relevantes e vamos discuti-los separadamente, na tentativa de melhor explorar o assunto: crítica ao cuidado oferecido por alguns profissionais, a necessidade de preparo do profissional para cuidar de famílias de portadores de transtorno mental e a importância do profissional enquanto agente de desinstitucionalização e reinserção social do portador de transtorno mental.

\section{Crítica ao cuidado oferecido por alguns pro- fissionais}

Ao falar do cuidado oferecido pelos profissionais aos portadores de transtornos mentais nas instituições psiquiátricas, "[...] chama-nos a atenção a evidente dissociação entre o discurso e a prática. Discursos cativantes que recorrem abundantemente a chavões como a liberdade do doente mental, humanização do tratamento, combate a repressão etc, convivem com uma prática assistencial mecânica e rotineira, fechada dentro de consultórios em entrevistas rápidas e superficiais. Outras vezes aqueles belos discursos convivem com a absoluta inação, com o nada a fazer e apenas a discursar numa prática medíocre e apoucada[...]". ${ }^{10: 124}$

É incrível como essa prática do discurso dife- rente da realidade é comum em saúde mental. Apesar de os profissionais trabalharem em equipe, o trabalho é solitário e individual, mesmo em instituições desenvolvidas nos moldes da desinstitucionalização como são os CAPSs. Um dos estudos retrata, entre outras coisas, a dificuldade de um CAPS para manter suas atividades. [...] frente ao relato de cada pessoa, os profissionais presentestecem comentários, orientandoouesclarecendo,porexemplo, sobre a continuidade do uso da medicação como meio de manter controle decrise; sobreolocal ondepoderáconseguira medicação, uma vez que o serviço, não dispondo de qualquer medicação, emite somente a receita[...]. O serviço, não dispondo de medicação, oferece uma dificuldade a mais, visto que a pessoa tem que se deslocarpor regióes, muitas vezes, desconhecidas, obrigando-a a gastos com transporte tempo, aliado às dificuldades de alguém que não tem prática de reivindicar, não raro, percebendo adssistência à qual tem direito como uma benesse, umato decaridade(3T-Enf).

Um fator igualmente importante a ser discutido é referente às desculpas apresentadas pelos profissionais componentes das equipes para executar um trabalho efetivo e satisfatório com portadores de transtornos mentais e seus familiares. $\mathrm{O}$ atendimento às famílias em hospitais psiquiátricos tradicionais muitas vezes a coloca à margem do tratamento e os limites de sua participação são claramente delimitados pelos profissionais e pelas normas da instituição. ${ }^{11}$ "[...] $\mathrm{Na}$ melhor das hipóteses, são realizadas entrevistas ou reuniões com familiares, que muitas vezes têm o objetivo de colher informações complementares ou mesmo mais fidedignas sobre o próprio doente, pois este é tido como tendo limites para fornecê-las [...]". 11:203

No entanto, o trabalho extramuros, deve ser diferente, e os principais atores desta atividade são a família e os profissionais. Mas para isso acontecer os profissionais precisam ter uma nova visão da família e começar a inseri-la em um "[...] posto privilegiado de sua ação[...]". 11: 204 Alguns estudos analisados retrataram falhas na atuação dos profissionais junto às famílias:[...]pode-se concluir que os enfermeiros não estão dando o devido valor a esse aspecto assistencial [...] pode-se afirmar, portanto, que a orientação efetiva dos familiaresnãotem ocorrido de modo satisfatório[...] a falta de atuação do enfermeiro nos programas deeducaçãoparapacientes efamiliares, comofoiconstatadona revisão de literatura realizadaenos dados colbidos, não pode ser justificada (8D-Enf).[...] Pode-sepensar que a equipe de saúde orienta-os sem saber se são estas as informaçôes que os mesmosgostariam desaber; provando assim que não existeuma interação entre equipe de saúde-paciente e família (11D-Enf).

É possível identificar nos relatos acima que o despreparo dos profissionais para trabalhar interdiscipli- 
narmente com famílias é evidente, e como conseqüência disso, eles desenvolvem uma assistência deficiente e de má qualidade. Por isso muitos estudos retrataram a necessidade de qualificação do profissional.

\section{A necessidade de preparo do profissional para cuidar de famílias de portadores de transtor- no mental}

Ao falarem do ensino de enfermagem e da reforma psiquiátrica, alguns autores ${ }^{12}$ revelam desinformação por parte dos alunos sobre o tema, mas asseguram que isto não é exclusivo dos acadêmicos. Revelam que alguns professores também estão desinformados e até admitem a sua contradição entre o discurso e a prática. No entanto, os acadêmicos entrevistados reiteram que há superficialidade do conhecimento psiquiátrico reproduzido e a desarticulação deste com a história de vida dos portadores de transtornos mentais reforçam a separação entre teoria e prática dificultando, assim, o trabalho interdisciplinar.

O relato acima me faz refletir... Se os professores e acadêmicos, principalmente os acadêmicos, aqueles que estão sendo preparados para o cuidado dos portadores de transtorno mental e sua família apresentam desconhecimento relacionado a esse cuidado interdisciplinar com vistas à desinstitucionalização, imagino os demais que já estão na ativa e que sua formação não foi pautada na reforma psiquiátrica. Então, fica a indagação: como podemos mudar essa realidade?

Esse despreparo dos profissionais para trabalhar com o portador de transtorno mental e sua família no paradigma da desinstitucionalização foi retratado por alguns estudos: [...] observou-se a critica feita com relaçãoà falta de preparo dos funcionários, comoforma de manutenção do sentimento de medo isolamento do paciente. Os sentimentos deraiva, irritaçãoe revoltatambém aparecem nos depoimentosdosmembrosddequipe. Estedespreparoe (ou) dificuldadeem cuidar dopacientepsiquiátrico, aliado àconcepşão do doentemental comopotencialmenteagressivogeramidéíds deque o mesmo deveser assistidoem local especifico, separado das demaisespecialidades, oquenãocondizcomo movimento desubstituriçãodeum atendimentoeminentementecentradonomodelo manicomial paraatençãoemequipamentoscomoasemergências psiquiátricasem hospitaisgerais(10P).

Alguns estudos apontam a necessidade do preparo do profissional ainda na Universidade: [...] a possibilidade deser incluída nos cursos degraduação mudançascapazes dedesenvolverentreenfermeiros técricas deredaçãocentradas nopensamentofilosófico-cientifico. [... istocontribuiriapara a tradução dassensaçoés, sentimentos, idéias, enfim, percepções que chegamaoprofissional em sua relaçãocomo outro...um profissional preparado para cuidar do outro (4D-Enf).

É possível verificar, a partir dos exemplos, que há um descompasso entre o ensino e o serviço. $\mathrm{O}$ ensino e a prática em saúde mental estão desencontrados, em função de que os pressupostos da reforma psiquiátrica ainda não foram de todo transpostos para o desempenho cotidiano de cada profissional no serviço. É necessário apoio ao ensino de graduação e pós-graduação, com o objetivo de lançar outras possibilidades para a construção de uma nova prática, calcada nos pressupostos da desinstitucionalização e da reforma psiquiátrica, ${ }^{13}$ principalmente no que diz respeito à construção de um cuidado interdisciplinar ao portador de transtorno mental e sua família.

No entanto, a mudança na postura do profissional em relação ao portador de transtorno mental e sua família pode estar relacionada com as dificuldades que ele encontra na realidade ao lidar com essa clientela no dia-a-dia de sua atividade profissional. Isto foi evidenciado numa equipe de saúde da família e portadores de transtornos mentais e seus familiares quando pesquisados a respeito do atendimento em saúde mental neste programa. "[...] ficou evidente a incoerência entre as opiniões dos sujeitos quanto às orientações dos profissionais em relação aos tratamentos medicamentosos e a maneira como o paciente os utiliza. Os profissionais precisam estar preparados para esta tarefa, visto que, diante do processo de reforma psiquiátrica, é fundamental a participação ativa do sujeito no seu tratamento, garantindo seus efeitos positi$\operatorname{vos}[\ldots .] ".]^{14.60}$

É possível observar na afirmativa acima a necessidade de se ter profissionais capacitados para trabalhar interdisciplinarmente em serviços extra-hospitalares com portadores de transtornos mentais e seus familiares.

\section{A importância do profissional enquanto agen- te da desinstitucionalização e reinserção so- cial do portador de transtorno mental}

A partir dos pressupostos da desinstitucionalização, é possível afirmar que para ela acontecer de fato é preciso preparar a comunidade para a convivência com o portador de transtorno mental. Acreditamos que é necessário reconstruir vínculos e isso só pode acontecer se houver a desmistificação da periculosidade e da incapacidade do portador de transtorno mental de viver em sociedade. Esse é um pro- 
cesso lento, mas que precisa ser muito bem planejado e amparado, pelo envolvimento de vários segmentos da sociedade, pois, é preciso integrar os interesses da população (famílias, usuários, profissionais e comunidade em geral) e interesses políticos associados à melhoria da qualidade de vida da população, com a implantação de leis e decretos que assegurem uma assistência adequada e digna ao portador de transtorno mental e sua família.

Alguns estudos apontaram esse importante papel do profissional:[...]enfim, a desinstitucionalizaçãoéum processo queseinscrevenumadimensĩoética, poisétambémuma luta contra o estigma, a exclusão, a violência; a desinstitucionalização intercedepela epara a solidariedade, a convivenciaentre as diversidadese os diferentes.[...] àmedidaem que procura desconstruir o muro cientifico que se construiuem torno da loucura, ou seja, requer uma postura profissional diferente (4RT).

É possível perceber a partir deste relato que o profissional deve iniciar esta mudança pela sua postura ética junto ao portador de transtornos mentais e sua família, e depois trabalhar na desconstrução de saberes antigos calcados no estigma, no isolamento e na discriminação. E isso a nosso ver torna-se muito mais fácil se for trabalhado e discutido em uma equipe interdisciplinar.

Um dos papéis do profissional no processo de desinstitucionalização é o de reinserção social do portador de transtorno mental na família e na comunidade, e essa afirmativa esteve presente em muitos estudos, independente da formação profissional do autor do estudo analisado.[...] o profissional deve ter uma postura frente do ser que adoecee sua familia, demodo que o valorizena expressão de sua dor. É preciso que oprofissional crie condições paraque opaciente possa comunicar seu sofrimento. Oprofissional deve dar ênfase no projeto de intervenção à saúdee reinserção social do doente, focalizando a produção da vida, de sentido, de sociabilidade(6P).

O trabalho dos profissionais na reabilitação social dentro da reforma psiquiátrica está centrado não no modelo biologicista, mas sim em questões de habitação, de trabalho e das redes sociais; a centralização do trabalho dos profissionais está na história de vida da pessoa e que esse é um ponto relevante para a reabilitação social. ${ }^{15} \mathrm{E}$ pela complexidade desse processo é quase que impossível alcançar êxito se o trabalho não for realizado de forma interdisciplinar. Por isso ao trabalhar com famílias e reabilitação social e assim obter um resultado satisfatório é fundamental a interdisciplinaridade e a intersetorialidade e com isso estabelecer parcerias com a família e a comunidade. ${ }^{16}$

Os novos serviços de saúde mental, característicos do processo de reforma psiquiátrica são muito distintos em seus perfis. Costumam desenvolver atividades terapêuticas muito peculiares, o que exige de todos os profissionais da equipe versatilidade na busca por adequar a necessidade da clientela ao plano terapêutico global do serviço. ${ }^{13}$ Além do mais é importante destacar que para a desinstitucionalização realmente acontecer é preciso o envolvimento de toda a sociedade e, um estudo revelou esta preocupação:[...] sea desinstitucionalização nãofor avaliadapor todos os ângulos, setransformaráem uma ação paliativa enuma desobrigação do Estado[...] a desinstitucionalização éresponsabilidade de toda sociedade (3RE).

Sendo a desinstitucionalização uma responsabilidade de toda a sociedade, cabe aos profissionais estarem atentos para os sentimentos de ambigüidade que a família vive para assim ampará-la e ajudá-la nas suas dúvidas e dificuldades, levando em consideração o número de serviços extramuros para atender o cliente e sua família e a preparação dos profissionais para exercer tal atividade. ${ }^{17}$

\section{CONSIDERAÇÕES FINAIS}

O trabalho interdisciplinar em saúde mental é um dos pressupostos para que a desinstitucionalização seja efetiva, porém conforme pode ser observado neste estudo os profissionais que atuam nesta área apresentam dificuldades em desenvolver essa forma de trabalho. Porém é fundamental enquanto profissional da enfermagem estarmos atentos para o trabalho em equipe, principalmente em saúde mental, pois os resultados irão beneficiar o cliente e os profissionais, já que as questões que envolvem a saúde mental e família são complexas e precisam envolver mais de uma disciplina, ou seja, mais de um saber específico.

Enquanto docentes universitários precisamos preparar os acadêmicos para o trabalho interdisciplinar em saúde mental com famílias, pois isto pode levar a dois aspectos positivos: 1) favorecer o crescimento do profissional e da disciplina enquanto ciência e 2) melhorar as condições de cuidado oferecido à clientela atendida, aumentando a probabilidade da melhora na qualidade de vida e oferecendo um cuidado de maior abrangência.

No entanto, apesar de muitos esforços, trabalhar interdisciplinarmente ainda se constitui um desafio ao qual precisamos nos empenhar vislumbrando um cuidado adequado ao portador de transtorno mental e sua família no paradigma da desinstitucionalização. 


\section{REFERÊNCIAS}

1 Rotelli F. Desinstitucionalização: uma outra via. In: Nicácio MF, organizador. Desinstitucionalização. São Paulo: Hucitec; 1990. p. 112-29.

2 Basaglia F. A instituição negada: relato de um hospital psiquiátrico. Rio de Janeiro: Graal; 1985.

3 Boff L. Saber cuidar: ética do humano, compaixão pela terra. Petrópolis: Vozes; 2003.

4 Chaves MM. Complexidade e transdisciplinaridade: uma abordagem multidimensional do setor saúde. [citado 2002 Maio 24]. Disponível em: http//wwwm.cufrj.br/ftp/ complex.doc

5 Gil AC. Métodos e técnicas de pesquisa social. 5 a ed. São Paulo: Atlas; 1999.

6 Bardin L. Análise de conteúdo. Lisboa: Edições 70; 1977.

7 Amarante P. Algumas considerações históricas e outras metodológicas sobre a reforma psiquiátrica no Brasil. In: Amarante P, organizador. Loucos pela vida: a trajetória da reforma psiquiátrica no Brasil. Rio de Janeiro: Fiocruz; 2003. p. $87-123$.

8 Nogueira-Martins LA. Saúde mental dos profissionais de saúde. In: Botega NJ, organizador. Prática psiquiátrica no Hospital Geral: interconsulta e emergência. Porto Alegre: Artmed; 2002, p.130-44.

9 Waidman MAP, Koga M, Stefanelli MC. Utilização da comunicação na prática da equipe multiprofissional de uma instituição psiquiátrica. Cogitare Enferm.1997; 2(1): 82-5.
10 Martins MB. A discriminação do doente mental. In: $\mathrm{D}^{\prime}$ Incao MA, organizadora. Doença mental e sociedade: uma discussão interdisciplinar. Rio de Janeiro: Graal; 1992. p. 123-7.

11 Wetzel C. Trabalhando junto à família em um serviço comunitário de atenção à saúde mental. Cad IPUB. 2000; 6(19):203-10.

12 Kantorsk LP, Silva GB. Ensino de enfermagem e reforma psiquiátrica. Pelotas: UFPel; 2001.

13 Fraga MNO, Souza AMA.; Santos MSO. Atuação da enfermagem nos serviços de saúde mental: uma experiência em um CAPS de Fortaleza. Cad IPUB, 2000; 7(19):188201.

14 Koga M. Programa de saúde da família de Maringá: opinião sobre a atenção à saúde mental [tese]. Ribeirão Preto (SP): Escola de Enfermagem da Universidade de São Paulo/EERP; 2003.

15 Hirdes A. Reabilitação social: dimensões teórico-práticas do processo. Erechim: EdiFAPES; 2001.

16 WaidmanMAP, MarconSS, Radovanovic CAT, SilvaDMPP. Promover a vida: uma modalidade de cuidado a saúde na família e na comunidade. Texto Contexto Enferm. 2003, jul-set; 12(3):332-41.

17 Abruzzese E, Del Giudice G, Dell'acqua G, EvaristoP, Impagnatiello M, Reali M, et al. Families \& services in desinstitutionalization. Triesti. 1996; 1:209-28. 